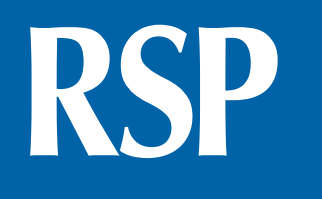

http://www.rsp.fsp.usp.br/
Revista de Saúde Pública

\title{
Nonadherence to immunosuppressives and treatment in kidney transplant: ADHERE BRAZIL Study
}

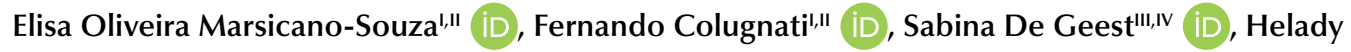 \\ Sanders-Pinheiro ${ }^{1,11}$ iD \\ I Universidade Federal de Juiz de Fora. Hospital Universitário. Unidade de Transplante Renal. Juiz de Fora, MG, \\ Brasil \\ " Núcleo Interdisciplinar de Estudos e Pesquisas em Nefrologia (NIEPEN). Juiz de Fora, MG, Brasil \\ III University of Basel. Institute of Nursing Science. Department of Public Health. Basel, Switzerland \\ Iv KU Leuven. Academic Centre for Nursing and Midwifery. Department of Public Health and Primary Care. \\ Leuven, Belgium \\ On behalf of the ADHERE BRAZIL study team*
}

\section{ABSTRACT}

OBJECTIVE: To estimate the prevalence and variability of nonadherence to immunosuppressives and nonpharmacological treatment across kidney transplantation centers and two health access-disparate regions in Brazil.

METHODS: In a cross-sectional design, a random multistage sample of 1,105 patients was included, based on center transplantation activity (low/moderate/high) and region (R1: North/Northeast/Mid-West; and R2: South/Southeast). Nonadherence to immunosuppressives

* joint 1 st authorship (implementation phase) was assessed using the Basel Assessment of Adherence to Immunosuppressive Medications Scale (BAASIS) ${ }^{\odot}$. Self-report questionnaires assessed nonadherence to physical activity, smoking cessation, alcohol intake, and appointment keeping. We compared regions using the adjusted- $\chi^{2}$ or t-test.

RESULTS: Most patients were men (58.5\%), white (51.4\%), and had a mean age of 47.5 (SD = 12.6) years. Regarding kidney transplantation centers, $75.9 \%$ were from $\mathrm{R} 2$ and $38.2 \%$ had low activity. The patients in $\mathrm{R} 2$ were older, white-majority, had more frequently steady partners, and received peritoneal dialysis. Nonadherence to immunosuppressives ranged from $11-65.2 \%$; $44.5-90 \%$ to physical activity; $0-23.7 \%$ to appointment keeping; and $0-14 \%$ to smoking cessation. The total prevalence of nonadherence and by region (R1 versus $\mathrm{R} 2$ ) were: for immunosuppressives, $39.7 \%$ ( $44.9 \%$ versus $38.1 \%, \mathrm{p}=0.18$ ); for smoking, $3.9 \%$ ( $1 \%$ versus $5 \%, \mathrm{p}<0.001$ ); for physical activity, $69.1 \%$ ( $71 \%$ versus $69 \%, \mathrm{p}=0.48)$; for appointment keeping, $13 \%$ ( $12.7 \%$ versus $12 \%, \mathrm{p}=0.77$ ); and for alcohol consumption, $0 \%$.

CONCLUSION: Despite differences among centers and high variability, only the nonadherence to smoking cessation was higher in the region with greater access to kidney transplantation. We suppose that differences in healthcare access may have been overcome by other positive aspects of the post kidney transplantation treatment.

DESCRIPTORS: Patient Nonadherence; Medication Nonadherence; Kidney Transplant; Multicenter Study; Health Services Accessibility. 


\section{INTRODUCTION}

After kidney transplantation (KT), it is essential that transplant patients, who are considered chronically ill, adequately follow the proposed treatment to reduce the risks of graft rejection and the progression of existing comorbidities, and the development of new ones. KT treatment is complex and involves adherence to immunosuppressives and nonpharmacological treatment components (regular physical activity, smoking cessation, reducing alcohol intake, and appointment keeping) ${ }^{1-3}$.

The prevalence of nonadherence to immunosuppressives is $28-67 \%$ depending on casefinding methods, operational definitions, and measurement tools ${ }^{1,4-6}$. A seven-fold increase in graft failure, as well as a clear association with acute rejection episodes, worse graft function, higher morbidity, and higher costs to health systems, have been reported ${ }^{5,6}$. Fewer studies have assessed the adherence to nonpharmacological treatment in KT. The reported prevalence of nonadherence to physical activity is $21.8-84 \%$, which is also driven by variability in methods $\mathrm{s}^{7-9}$.Inadequate physical activity can increase the risk for cardiovascular disease, which consequently relates to mortality and lower graft survival ${ }^{9,10}$. For smoking, the prevalence is $2.8-4.0$ cases per 100 patients per year? ${ }^{7}$ This behavior is also associated with cardiovascular diseases, and smoking cessation is recommended upon the diagnosis of chronic kidney disease ${ }^{10}$. Concerning alcohol consumption, post-transplant abuse is associated with poor medication adherence, which may increase the risk of graft loss and death ${ }^{11}$. Another fundamental but rarely studied behavior is the frequency of appointment keeping. Ranging from 2.5 to $14.6 \%$, nonadherent patients had a 1.5-fold increased risk of acute rejection and a $65 \%$ higher chance of graft loss ${ }^{7,12}$.

The ecological model proposes that adherence to these complex behaviors is a result of the interaction of multilevel factors, placing the patient at the center and influenced by factors from the healthcare provider/family (micro-), the transplant center (meso-), and the health care system (macro-) levels ${ }^{12}$. Some studies have corroborated this framework in transplantation ${ }^{13,14}$. While most reports have focused on patient-level factors, variables related to the micro- and meso-levels have been understudied. Should these factors be modifiable, they could be potential targets for interventions. For example, multidisciplinary follow-up for KT recipients based on the chronic care model, with continuous assessment of adherence as the " $5^{\text {th }}$ vital sign" may be cited, as well as the provision of support for self-management by health care professionals such as nurses, pharmacists, or physical therapists, to decrease nonadherence to immunosuppressives and physical inactivity ${ }^{15,16}$.

Brazil is a country of continental extension that ranks second in the absolute number of KTs worldwide, performed by the largest public transplant program ${ }^{17}$. However, even with a full-coverage healthcare system, there are regional disparities regarding access to KT. Examination of the Brazilian Transplant Registry ${ }^{18}$ revealed two distinct regions based on transplant activity: the South/Southeast states with elevated organ donation and transplantation; and the Northeast, Mid-West, and North states showing lower performances $^{18}$. Out of the 5,923 KTs performed in Brazil in 2018, 3,111 were performed in the Southeast, 1,457 in the South, 1,032 in the Northeast, 245 in the Mid-West, and 78 in the North $^{18}$. Data regarding access to general health services shows the same profile. Access to healthcare services has been easier in the South and Southeast states, with a higher number of medical appointments and doctors. Greater access is also associated with the higher grades of socioeconomic parameters statuses of these regions ${ }^{19,20}$.

The numbers of KT centers and healthcare professionals' teams mirror the variations in healthcare access, and these altogether are translated in these two profiles based on KT activity $^{18}$. Considering the ecological framework discussed above, access to health care, and hence to KT centers, can be considered a meso-level characteristic that influence adherence behaviors after receiving a kidney graft ${ }^{12}$. An improved quality of care provided by each KT center may, therefore, result in better clinical outcomes. Then, we believed the regional disparities offer a unique opportunity to study their influence on adherence to 
immunosuppressives and nonpharmacological treatment in KT recipients. Besides, the results could enable the design of individualized interventions to reduce the nonadherence rate in these settings.

This study aimed to estimate the prevalence and variability of nonadherence to immunosuppressives and nonpharmacological treatment across $20 \mathrm{KT}$ centers and in the two health access-disparate regions in Brazil.

\section{METHODS}

\section{Design, Sampling, and Setting}

This study utilized data from the multicenter ADHERE BRAZIL study (ClinicalTrials.gov on 10/10/2013, NCT02066935), a cross-sectional study aimed at estimating the prevalence of nonadherence to immunosuppressives and nonpharmacological treatment among Brazilian transplant populations across different regions with different access to healthcare services. The study also included a comprehensive evaluation of factors associated with nonadherence in $20 \mathrm{KT}$ centers in Brazil ${ }^{21}$.

The ADHERE BRAZIL study applied a multistage sampling strategy based on the transplantation activity of each center (low, moderate, and high) and the health access-disparate regions [Northeast/North/Mid-West (R1) and South/Southeast (R2)] ${ }^{18,21}$. The KT activity was based on a pre-existing classification for heart transplant ${ }^{18}$ and further submitted to a panel of Brazilian transplant nephrologists ${ }^{21}$. Transplant activity at the center level was defined as: low, less than $50 \mathrm{KTs} /$ year; moderate, $50-150 \mathrm{KTs} /$ year; and high, more than $150 \mathrm{KTs} /$ year $^{21}$. For the health access-disparate regions, R1 and R2, we considered the number of KTs performed per number of inhabitants during the last ten years ${ }^{18}$.

The 20 centers were chosen by convenience; the inclusion criteria involved obtaining consent for participation from their coordinators and the performance of at least $10 \mathrm{KTs}$ per year over the five years preceding the start of the study $(2010-2014)^{21}$. The selection of centers was also guided to keep a similar epidemiological profile when compared to the country. Patients scheduled for regular outpatient visit appointments were randomly selected based on the following inclusion criteria: age $>18$ years, more than one post-transplant year, ability to understand the objectives of the study, and willingness to sign the informed consent form. The detailed description of the methodology (sample size, sample strata, theoretical framework, etc.) has been previously reported ${ }^{12,21}$ and adapted from the BRIGHT Study. ${ }^{13}$

\section{Variables and Measurements}

The characteristics of the participating centers were assessed through structured interviews with their respective coordinators to obtain the following variables: number of beds available in the transplant center hospital [small/medium hospital (up to 150 beds); large hospital (151-500 beds); large specialized hospital ( $>500$ beds)]; satisfaction with waiting room structure (yes versus no); patient follow-up by the same healthcare professional (yes versus no); multiprofessional team by Brazilian law [yes (doctor + nurse + nutritionist + psychologist + social worker) versus no]; continuous education of the KT team (yes versus no); clinical guidelines (yes versus no); clinical research (yes versus no); electronic medical records (yes versus no); and waiting room educational activities (yes versus no). ${ }^{21}$ The interview with patients included: satisfaction with the number of health professionals (yes versus no); difficulties in accessing the center by public transportation (yes versus no); time of medical consultation (15 versus 30 minutes); satisfaction with the schedule system of the transplant center (yes versus no); difficulties in scheduling appointments (yes versus no); adequacy of the frequency of consultation (yes versus no); adequacy of time of consultation(yes versus no) ${ }^{21}$. 
The sociodemographic characteristics of patients were collected through interviews and medical records: age (years), sex (male or female), race (white versus non-white), marital status (steady partner versus not), education level [illiterate (0-4 years), elementary school (4-8 years), high school (> 8 to 11 years), college ( $>11$ years)], religion (Catholic, Protestant, Other), employment (active work versus no active work), and family income (up to 1 reference wage, $>1$ to 3 wages, $>3$ to 5 wages, more than 5 wages). Clinical data were collected by medical record review: pre-transplantation treatment time (months), pre-transplant treatment modality (hemodialysis, peritoneal dialysis, preemptive), donor type (living versus deceased donor), post-transplant time (years), latest creatinine levels, and episodes of acute rejection (yes versus no) ${ }^{6,13,21}$.

For the diagnosis of nonadherence to immunosuppressives, the implementation phase of medication adherence was evaluated using the Brazilian Portuguese validated version of the Basel Assessment of Adherence with Immunosuppressive Medication Scale (BAASIS) ${ }^{\circledR 22}$. This self-report questionnaire is composed of four dimensions frequently associated with the failure of the implementation phase (taking and timing adherence, drug holidays, and dose reduction). Patients who reported any deviation in any of the items within the preceding four weeks were considered nonadherent ${ }^{22}$.

Nonadherence to nonpharmacological treatment components (physical activity, smoking cessation, alcohol consumption, and appointment keeping) was evaluated through the patient interview during routine office consultations ${ }^{21}$. A patient who performed less than 150 minutes of activity per week was considered nonadherent to the physical activity recommendations ${ }^{23}$. For smoking, we considered nonadherent those who consumed cigarettes during the data collection period ${ }^{24}$. nonadherence to alcohol ingestion was a daily alcohol consumption of one drink for women and two for $m^{25}{ }^{25}$. Regarding the frequency of consultations, we defined nonadherence as missing more than one of the last five scheduled appointments ${ }^{21}$.

\section{Data Collection}

Data were collected from December 2015 to April 2017 during routine consultations in the transplantation service through the Research Electronic Data Capture system, a secure internet program that stores data and can be remotely powered by trained personnel $^{23}$. All coordinators were trained to use the system for the data collection. Patients scheduled for consultation wererandomly selected by a computerized method, and those who were eligible would receive information about the ADHERE study to provide written consent ${ }^{21}$.

\section{Statistical Analysis}

Categorical variables were described by frequency and percentage, while continuous variables by central tendency and dispersion measure, where appropriate.

Because the sample was designed to be self-adjusted ${ }^{21}$, the comparisons between regions (R1 and R2) in nonadherence to immunosuppressives and nonpharmacological treatment components (in terms of centers, demographics, and clinical data) were analyzed using the adjusted $\chi^{2}$ test or $\mathrm{t}$-test. All variables are presented with their respective $95 \%$ confidence intervals $(95 \% \mathrm{CI})$. The analyses were performed using STATA version 14 (StataCorp LP, College Station, TX, USA).

\section{Ethical Considerations}

The study was approved by the Ethics Committee of the University Hospital of the Universidade Federal de Juiz de Fora $(691,120)$ and registered nationally (CAAE 27972914.1.1001.5133). Participating centers also submitted the protocol for approval by their local ethics committee. All patients signed informed consent forms before data collection. 


\section{5,785 patients screened}

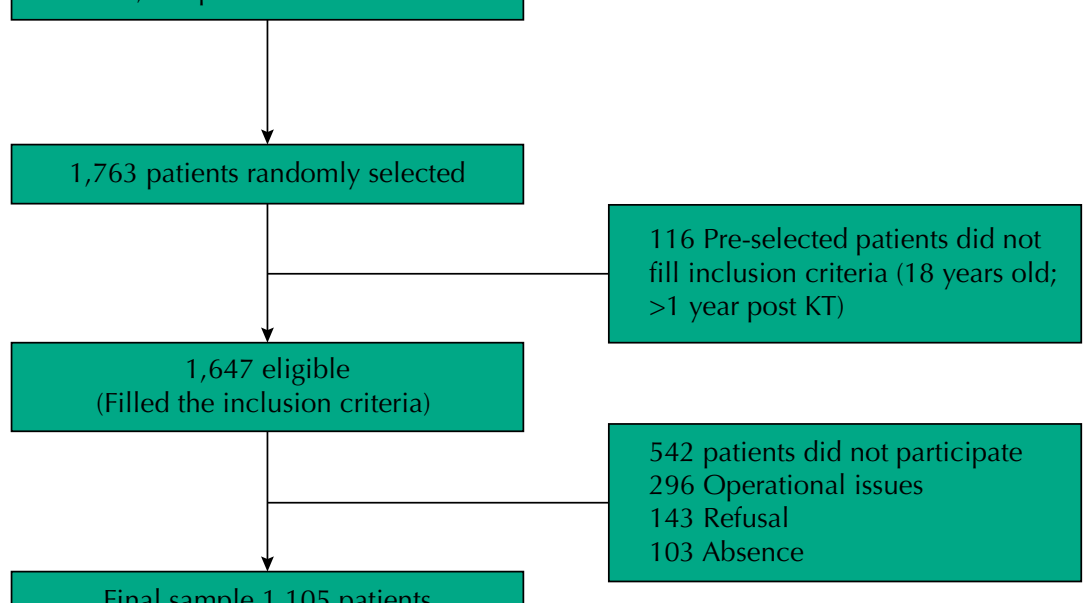

Final sample 1,105 patients

Figure 1. Flowchart of enrolment of KT patients. KT - kidney transplant.

Table 1. Centers and health system characteristics data.

\begin{tabular}{|c|c|c|c|c|c|c|c|}
\hline Variable & $\begin{array}{l}\text { All regions } \\
(\mathrm{N}=1105) \\
\%(\mathrm{n})\end{array}$ & $95 \% \mathrm{Cl}$ & $\begin{array}{l}\text { N/NE/MW } \\
(\mathrm{N}=267) \\
\%(n)\end{array}$ & $95 \% \mathrm{Cl}$ & $\begin{array}{c}\text { South/Southwest } \\
\left(\begin{array}{c}N=838) \\
\%(n)\end{array}\right.\end{array}$ & $95 \% \mathrm{Cl}$ & $\mathbf{p}^{*}$ \\
\hline \multicolumn{8}{|l|}{ Center characteristics } \\
\hline \multicolumn{8}{|l|}{ Number of beds of the transplant center hospital } \\
\hline Small/medium hospital (till 150 beds) & $7.8(86)$ & $1.92-26.6$ & $7.5(20)$ & $5.7-53.1$ & $7.9(66)$ & $1.4-32.4$ & 0.26 \\
\hline Large hospital (151 to 500 beds) & $53.6(592)$ & $26.9-78.2$ & $81.0(216)$ & $31.8-97.4$ & $44.9(376)$ & $26.9-78.2$ & \\
\hline Special large hospital: $>500$ beds & $38.6(427)$ & $17.0-65.8$ & $11.6(31)$ & $9.1-65.2$ & $47.3(396)$ & $16-77.5$ & \\
\hline $\begin{array}{l}\text { Multiprofessional team, Brazilian law Doctor+ } \\
\text { nurse + nutritionist + psychologist + social } \\
\text { worker (yes) }\end{array}$ & $80.1(886)$ & $50.8-94$ & $92.5(247)$ & $46.8-99.4$ & $76.2(639)$ & $41.0-93.6$ & 0.59 \\
\hline Clinical guidelines (yes) & $94.0(1039)$ & 74.9-98.8 & $100.0(267)$ & 100.0 & $92.1(772)$ & $67.5-98.5$ & 0.48 \\
\hline Continuous education directed to KT team (yes) & $97.7(1080)$ & 82.0-99.7 & $100.0(267)$ & 100.0 & $97.0(813)$ & $76.6-99.6$ & 0.61 \\
\hline Electronic medical records (yes) & $53.8(595)$ & $25.6-79.7$ & $29.6(79)$ & $4.8-77.5$ & $61.6(516)$ & $25.0-88.5$ & 0.28 \\
\hline Waiting room educational activities (yes) & $47.9(529)$ & $21.3-75.6$ & $57.7(154)$ & $12.6-92.7$ & $44.7(375)$ & $16.0-77.4$ & 0.68 \\
\hline Not satisfied with waiting room structure* (yes) & $42.7(427)$ & $32.7-53.4$ & $71.9(192)^{*}$ & $54.6-84.4$ & $33.4(280)^{*}$ & $25.3-42.7$ & 0.005 \\
\hline $\begin{array}{l}\text { Not satisfied with the number of health } \\
\text { professionals* (yes) }\end{array}$ & $44.6(493)$ & $44.9-64.9$ & $61.0(163)^{*}$ & $52.2-69.2$ & $39.6(330)^{*}$ & $27.4-53.1$ & 0.01 \\
\hline $\begin{array}{l}\text { Difficulties in accessing the center by public } \\
\text { transportation (yes) }\end{array}$ & $13.7(152)$ & $6.2-27.9$ & $13.8(37)$ & $6.2-27.9$ & $13.7(115)$ & $6.3-27.2$ & 0.69 \\
\hline \multicolumn{8}{|l|}{ Average total time of medical consultation } \\
\hline 15 minutes & $31.4(348)$ & $12.9-58.7$ & $27.3(73)$ & $3.8-78.1$ & $32.8(257)$ & $11.6-64.3$ & 0.83 \\
\hline 30 minutes & $68.5(757)$ & $41.2-87.0$ & $72.6(194)$ & $21.8-96.2$ & $67.1(563)$ & $35.6-88.3$ & \\
\hline $\begin{array}{l}\text { Not satisfied with the schedule system of the } \\
\text { transplant center (yes) }\end{array}$ & $22.9(253)$ & $13.9-35.4$ & $31.2(83)$ & $19.0-46.6$ & $20.3(170)$ & $9.6-37.9$ & 0.27 \\
\hline Difficulties in scheduling appointments (yes) & $10.3(114)$ & $6.2-16.8$ & $16.2(43)$ & $6.4-35.4$ & $8.5(71)$ & $4.3-16.1$ & 0.23 \\
\hline Adequacy of the frequency of consultation* (yes) & $86.4(955)$ & $83.0-89.5$ & $87.9(234)^{*}$ & $81.3-92.4$ & $86.1(721)^{*}$ & $81.9-89.5$ & 0.02 \\
\hline Adequacy of time of consultation (yes) & $94.8(1,046)$ & $93.1-96.1$ & $93.2(248)$ & $89.2-95.8$ & $95.3(798)$ & $93.6-96.6$ & 0.18 \\
\hline \multicolumn{8}{|l|}{ Health system } \\
\hline Private insurance & $23.4(259)$ & $19.3-28.0$ & $18.7(50)$ & $12.3-27.3$ & $24.9(209)$ & $20.4-30.0$ & 0.18 \\
\hline Lab exams by public health system & $90.3(997)$ & $83.6-94.5$ & $83.5(223)$ & $75.8-89.1$ & $92.6(744)$ & $84.5-96.2$ & 0.06 \\
\hline Refill of immunosuppressives in another city & $45.8(506)$ & $38.4-53.4$ & $52.2(139)$ & $42.1-62.2$ & $43.7(367)$ & $34.8-53.2$ & 0.12 \\
\hline Immunosuppressives refill in a distant place* & $54.0(596)$ & $46.3-61.5$ & 66.9 (178) & $62.9-70.6$ & 49.9 (418) & $40.5-59.3$ & 0.002 \\
\hline
\end{tabular}

Data are shown in mean + standard deviation or frequencies.

* We compare regions N/NE/MW (R1) versus South/Southwest (R2) by adjusted Chi-square test/95\%Cl or $\mathrm{t}$ test. 


\section{RESULTS}

\section{Sample Characteristics (Centers and Patients)}

At the 20 participating centers, 5,785 patients were screened. Of them, we randomly selected 1,763 patients; and from these, 1,647 met the inclusion criteria. We finally included 1,105 patients (participation rate, 67\%). The remaining were excluded due to operational issues $(\mathrm{n}=296)$, refusal for participation $(\mathrm{n}=143)$, and nonattendance to the consultations ( $\mathrm{n}=103$ ) (Figure 1).

Most centers of the ADHERE Brazil study ( $\mathrm{n}=17 ; 85 \%$ ) were of low or moderate KT activity and located in large hospitals (53.6\%). Dissatisfaction with the waiting room structure

Table 2. Socio-demographic and clinical data of patients of the total sample and of health access-disparate regions

\begin{tabular}{|c|c|c|c|c|c|c|c|}
\hline Variable & $\begin{array}{c}\text { All regions } \\
(\mathrm{N}=1105) \\
\%(\mathrm{n})\end{array}$ & $95 \% \mathrm{Cl}$ & $\begin{array}{c}\text { N/NE/MW } \\
\left(\begin{array}{c}N=267) \\
\%(n)\end{array}\right.\end{array}$ & $95 \% \mathrm{Cl}$ & $\begin{array}{c}\text { South/Southwest } \\
\begin{array}{c}(\mathbf{N}=838) \\
\%(n)\end{array}\end{array}$ & $95 \% \mathrm{Cl}$ & $\mathbf{p}^{*}$ \\
\hline \multicolumn{8}{|l|}{ Gender } \\
\hline Male & $58.5(647)$ & $54.2-62.7$ & $53.5(143)$ & $45.5-61.3$ & $60.1(504)$ & $56.0-64.0$ & 0.13 \\
\hline \multicolumn{8}{|l|}{ Race } \\
\hline White* & $51.4(586)$ & $41.1-61.5$ & $23.6(63)$ & $16.6-32.3$ & $60.2(505)$ & $46.2-72.8$ & 0.001 \\
\hline Age (years) & $47.5 \pm 12.6$ & - & $44.1 \pm 13.1$ & - & $48.6 \pm 12.2$ & - & 0.001 \\
\hline \multicolumn{8}{|l|}{ Education level } \\
\hline Illiterate (0-4y) & $7,8(86)$ & $4.9-12.0$ & $6.3(17)$ & $3.2-12.0$ & $8.2(69)$ & $4.7-13.9$ & 0.15 \\
\hline Elementary school (4-8 years) & $39.0(431)$ & $35.4-42.7$ & $32.2(86)$ & $24.1-41.6$ & $41.4(345)$ & $36.9-45.5$ & \\
\hline High school (> 8 to 11 years) & $38.3(423)$ & $33.9-42.8$ & $43.0(115)$ & $35.9-50.4$ & 36.7 (308) & $31.1-42.7$ & \\
\hline College $(<11$ years $)$ & $14,9(165)$ & $12.3-17.9$ & $18.3(49)$ & $15.2-22$ & $13.8(116)$ & $10.8-17.5$ & \\
\hline \multicolumn{8}{|l|}{ Marital Status } \\
\hline Stable partner* & $60.0(662)$ & $56.3-63.5$ & $54.3(144)$ & $48.0-60.5$ & $61.8(518)$ & $57.8-65.6$ & 0.04 \\
\hline Not employed* & 76.7 (848) & $73.3-79.8$ & $81.6(218)$ & $76.9-85.5$ & $75.1(630)$ & $71.3-78.6$ & 0.03 \\
\hline \multicolumn{8}{|l|}{ Family income } \\
\hline Until 1 reference wage & $25.4(281)$ & $19.2-32.8$ & $33.0(88)$ & $23.1-44.4$ & $23.0(193)$ & $16.6-31.0$ & 0.16 \\
\hline$>1$ to 3 wages & $52.7(582)$ & $46.4-58.8$ & $50.9(134)$ & $43.3-57$ & $53.5(448)$ & $45.8-61.0$ & \\
\hline$>3$ to 5 wages & $14.2(157)$ & $11.4-17.5$ & $9.7(26)$ & $5.2-17.4$ & $15.6(131)$ & $13.0-18.6$ & \\
\hline Up to 5 wages & $7.6(84)$ & $4.9-11.4$ & $7.1(19)$ & $4.8-10.3$ & $7.7(65)$ & $4.5-13.0$ & \\
\hline \multicolumn{8}{|l|}{ Religion } \\
\hline Catholic & $63.6(703)$ & $60.6-66.5$ & $68.5(183)$ & $65.5-71.3$ & $62.0(520)$ & $58.4-65.5$ & 0.45 \\
\hline Protestant & $26.0(287)$ & $23.3-28.7$ & $24.3(65)$ & $19.2-30.2$ & $26.4(222)$ & $23.3-29.8$ & \\
\hline Other & $10.5(116)$ & $1.0-3.6$ & $7.2(19)$ & $1.0-11.1$ & $11.4(96)$ & $1.2-3.8$ & \\
\hline Pre-KT treatment* & $93.0(1028)$ & $91.3-94.4$ & $97.0(259)$ & $95.1-98.1$ & $91.8(769)$ & $89.7-93.3$ & 0.05 \\
\hline Hemodialysis & $3.7(40)$ & $2.4-5.2$ & $1.9(5)$ & $0.7-5.1$ & $4.2(35)$ & $2.9-5.9$ & \\
\hline Peritoneal dialysis & $3.3(37)$ & $2.2-5.1$ & $1.1(3)$ & $0.3-4.3$ & $4.0(34)$ & $2.5-6.4$ & \\
\hline \multicolumn{8}{|l|}{ Preemptive } \\
\hline Pre-transplantation treatment time (months) & $40.4 \pm 40.4$ & - & $42.7 \pm 39.8$ & - & $39.6 \pm 40.5$ & - & 0.13 \\
\hline Post-transplant time (years) & $6.2 \pm 4.8$ & - & $6.0 \pm 4.9$ & - & $6.2 \pm 4.7$ & - & 0.77 \\
\hline \multicolumn{8}{|l|}{ Type of donor } \\
\hline Deceased & $65.2(721)$ & $55.8-73.5$ & $72.2(193)$ & $54.2-85.1$ & $63.0(528)$ & $52.9-72.1$ & 0.32 \\
\hline \multicolumn{8}{|l|}{ Acute rejection } \\
\hline Yes & $22.8(2)$ & $17.4-29.3$ & $19.4(52)$ & $15.1-24.6$ & 23.9 (198) & $17.1-32.2$ & 0.29 \\
\hline Last creatinine* & $1.6 \pm 0.83$ & - & $1.4 \pm 0.78$ & - & $1.6 \pm 0.84$ & - & 0.001 \\
\hline
\end{tabular}

Data are shown in mean + standard deviation or frequencies.

* We compare regions N/NE/MW (R1) versus South/Southwest (R2) by adjusted Chi-square test/ $95 \% \mathrm{Cl}$ or t test. 
was frequently reported (42.7\%). It was higher in R1 (71.9\% versus $33.4 \%, \mathrm{p}=0.005)$, as was dissatisfaction with the number of health professionals (overall, $44.6 \%$; $61 \%$ versus $39.6 \%$, $\mathrm{p}=0.01)$. The overall rate of consultation frequency adequacy was very high $(86.4 \%)$, and this was higher in $\mathrm{R} 1$ ( 87.9 versus $86.1 \%, \mathrm{p}=0.02$ ). The facility of immunosuppressives dispensing was considered too distant for most patients, mainly in $\mathrm{R} 1$ ( 66.9 versus $49.9 \%, \mathrm{p}=0.002$ ). However, the vast majority underwent their laboratory examinations in public health system facilities (90.3\%), more frequently in R2 than in R1 (92.6 versus 83.5\%, respectively). Other variables were similar between regions (Table 1).

Fifty-eight percent of patients were $58.5 \%$ male (53.5\% in R1 versus $60.1 \%$ in R2). Most of them self-declared as white (overall, $51.4 \% ; 23.6$ versus $60.2 \%$ ). In R2, the patients were older than those in $\mathrm{R} 1$ (48.6 [SD = 12.2] versus 44.1 [SD = 13.1] years, respectively). Regarding education level, $39 \%$ had $4-8$ years of schooling (32.2\% in R1 versus $41.4 \%$ in R2). Ninetythree percent underwent hemodialysis before transplantation ( $97.0 \%$ in R1 versus $91.8 \%$ in $\mathrm{R} 2$ ), and $65.2 \%$ received a deceased donor graft in all regions. The mean overall creatinine level was $1.6[\mathrm{SD}=0.83 \mathrm{mg} / \mathrm{dL}(1.4[\mathrm{SD}=0.78 \mathrm{mg} / \mathrm{dL}]$ in $\mathrm{R} 1$ versus $1.6[\mathrm{SD}=0.84 \mathrm{mg} / \mathrm{dL}]$ in R2) (Table 2).

\section{Prevalence of nonadherence to immunosuppressives and health behaviors}

The overall prevalence of nonadherence to immunosuppressives was 39.7\% (range, 11.0-65.2\%) among KT centers (Figure 2). When evaluating nonadherence to immunosuppressives by the four separate dimensions of the BAASIS ${ }^{\odot}$ (taking and timing, drug holidays, and dose reduction), the highest prevalence in the sample was in the deviations in timing (30.6\%), followed by nonadherence to immunosuppressives intake (14.3\%), drug holiday (6.0\%), and dose reduction (5.4\%) (Figure 3).

A

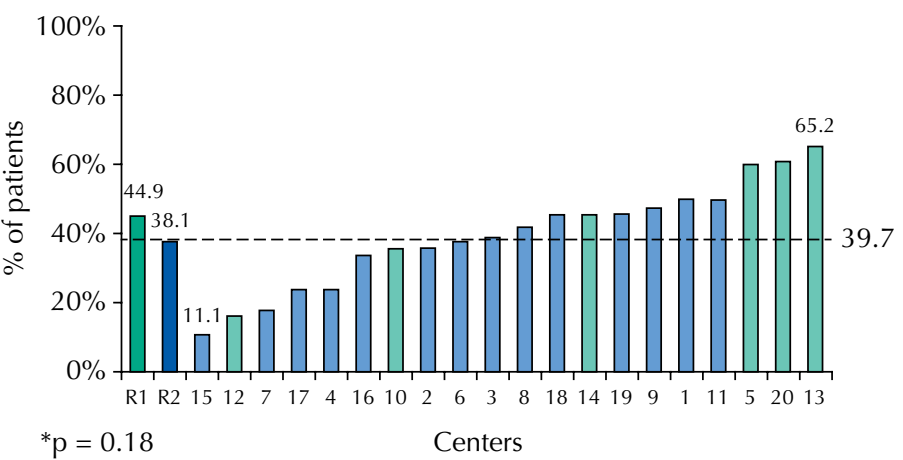

C

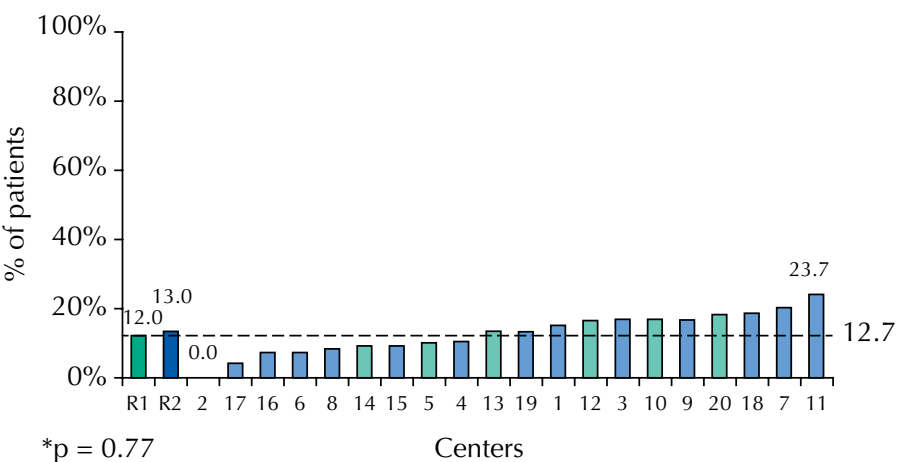

B Nonadherence to physical activity recommendation

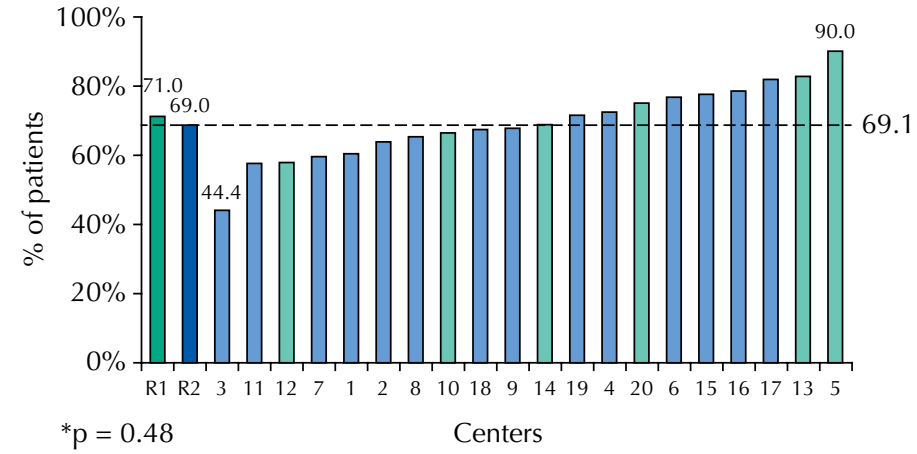

$\mathrm{D}$ Nonadherence to smoking quitting

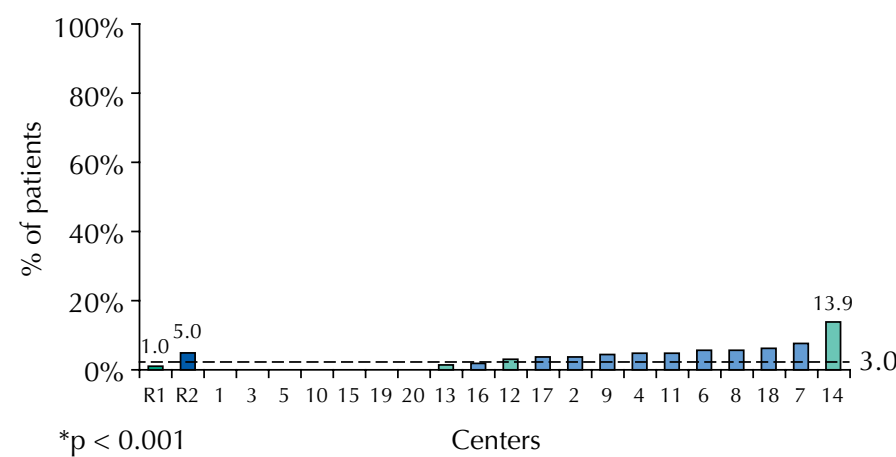

Figure 2. Nonadherence to immunosuppressives $(2 \mathrm{~A})$ and nonpharmacological treatment (2B: physical activity recommendations, $2 \mathrm{C}$ : scheduled appointments and, 2D: smoking cessation) in the total sample (dotted line), at each center (numbers in horizontal axis) and in health access-disparate regions. R1 = Northeast/North/Mid-West (green) and R2 = South/Southwest (orange). We compared the R1 versus $\mathrm{R} 2$ regions by adjusted Chi-square test. 
A

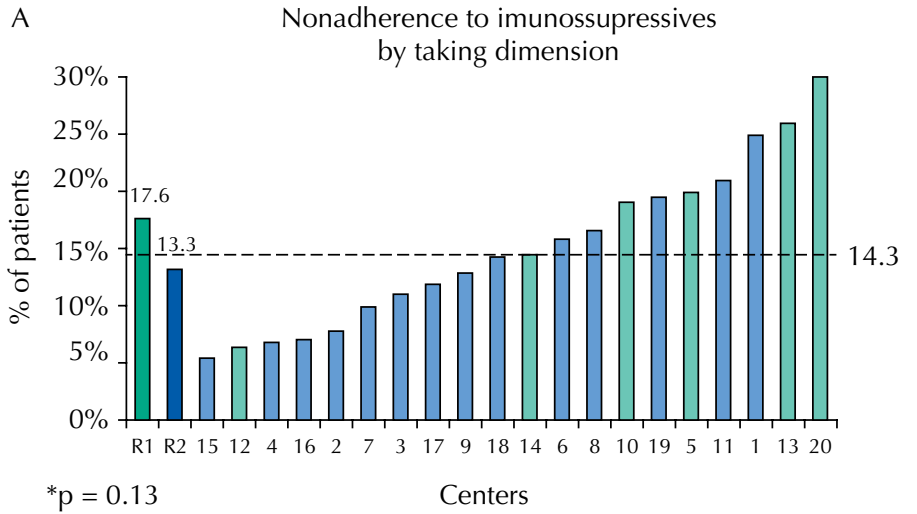

C

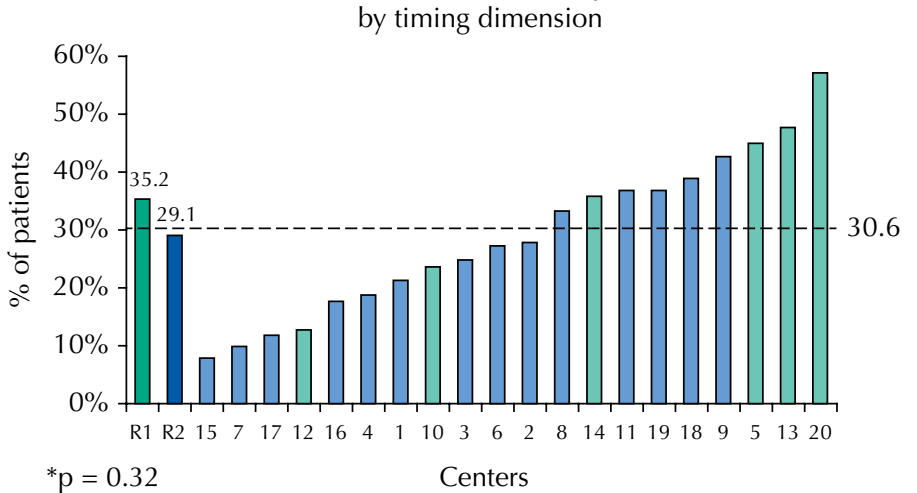

B

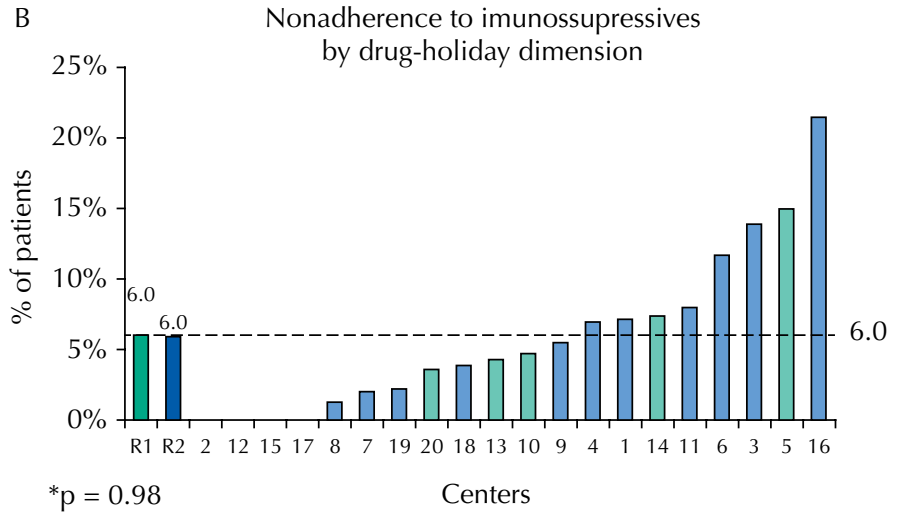

D

Nonadherence to imunossupressives by reducing dimension

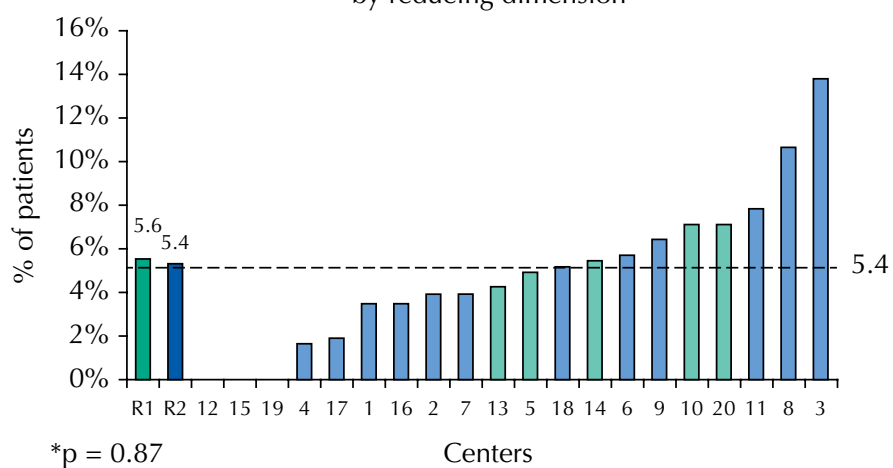

Figure 3. Implementation nonadherence to immunosuppressives by BAASIS ${ }^{\circ}$ scale dimensions [taking (2A), timing (2B), drug holidays (2C) and dose reduction (2D)] in total sample (dotted line), at each center (numbers in horizontal axis) and in health access-disparate regions. R1 = Northeast/North/Mid-West (green) and R2 = South/Southwest (orange). We compared the R1 versus R2 regions by adjusted Chi-square test.

Regarding nonpharmacological treatment components, the highest prevalence of nonadherence was to physical activity recommendations (less than $150 \mathrm{~min} /$ week), accounting for $69.1 \%$ (range, 44.5-90\%). Nonattendance of at least one of the last five scheduled appointments was $12.7 \%(0-23.7 \%)$. Only $3.9 \%$ (0-13.9\%) were current smokers, and all participants denied being heavy drinkers (Figure 2).

Comparing regions and the prevalence of nonadherence to nonpharmacological treatment, only nonadherence to smoking cessation was more frequent in the $\mathrm{R} 1$ region ( $5 \%$ versus $1 \%$; $<$ 0.001) (Figure 2).

\section{DISCUSSION}

This was the first multicenter study of KT patients to evaluate adherence to different health behaviors in Brazil. It is also the first study elucidating a panel of these risky behaviors in a variety of KT centers across the two health access-disparate regions of Brazil. We deemed the large sample size as one of the strengths of our study, alongside the sample design that aimed to approximately represent the Brazilian KT population, and the use of a theoretical framework, i.e., the ecological model ${ }^{12}$, to select potential multilevel correlates, which is uncommon in existing adherence studies.

The studied sample has demographic characteristics that reflect the KT population worldwide - age, male sex, deceased-donor type, and hemodialysis as previous treatment. We found that the schooling level and family income represented a specific epidemiological frame, particularly of a low socioeconomic level population. Furthermore, for the first time, some aspects of the clinical practice of KT centers have been analyzed and compared based 
on two healthcare access-disparate regions in Brazil. The higher dissatisfaction with the waiting room structure and with the number of health professionals reported by patients from R1, which supposedly had worse access, reinforced the hypothesis of limited health care availability, such as the greater distance to immunosuppressives dispensing facilities.

The highest frequency of nonadherence after KT in the entire sample and the studied regions was to physical activity. In one center, $90 \%$ of patients were physically inactive. Despite being understudied, the nonadherence to post-KT physical activity was estimated at $35-84 \%^{8,26,27}$, similar to what we found in our study. Physical activity helps prevent cardiovascular diseases, which is the major cause of post-transplant death and improves the quality of life $\mathrm{e}^{28}$. Although physical activity promotion programs have improved some aspects of physical performance, the evidence for their effects on graft outcomes is lacking. Therefore, physical activity programs are a promising area of research ${ }^{28}$.

The second highest prevalence of nonadherence was to immunosuppressives. We found a total prevalence of $39.7 \%$, similar to the previously reported $20-60 \%^{1,4,5}$, using self-report instruments for diagnosis. Interestingly, we found some effect, with the additional 7 points in the prevalence of $\mathrm{R} 1$ and a $\mathrm{p}$-value of 0.18 , nonadherence to immunosuppressives was similar in the two health access-disparate regions. There are currently no data on access to healthcare services for KT in Brazil. The universal access to health services provided by our public health system is challenged in some low socioeconomic level areas, which is reflected by the smaller number of consultations and health professionals ${ }^{29}$. The treatment of chronic kidney disease in its more advanced phase, - dialysis and transplantationis classified as highly complex, has differentiated reimbursement, and is often provided by a well-organized center/hospital. Thus, after KT, the patient has the opportunity to be followed in such a structured service, surpassing the other failures of the health system. However, we found no association between R1 and R2 in terms of the four BAASIS dimensions (immunosuppressives taking and timing, drug holidays, and dose reduction). Further studies, applying different methodologies to categorize health access, such as the five geographic regions or the human development index, could better explore this finding.

We found a high prevalence of patients not keeping their appointments for KT services (12.7\%). This figure varied widely among centers but not between the studied regions. This prevalence is one of the highest among the few available studies ${ }^{5,11}$. Strategies for decreasing nonattendance are feasible and could prevent this behavior, which is ultimately associated with graft loss ${ }^{11}$.

Nonadherence to smoking cessation was similar to that described by other KT studies, but this behavior was only one more frequent in $\mathrm{R} 2$. The highest nonadherence rate among services was $13.9 \%$. In this case, the higher prevalence of smokers in the $\mathrm{R} 2$ region can be attributed to the relatively better economic status of patients, favoring access to cigarettes ${ }^{30}$. Smoking is associated with an increased risk of cardiovascular death and a 50\% greater risk of graft loss when compared to ex-smokers. These findings suggest the need for greater emphasis on smoking cessation, even in the pre-transplantation period?

Alcohol dependence in the pre-transplantation phase is associated with a $38 \%$ increased risk of graft loss due to death and a $56 \%$ increased risk of transplant-related death ${ }^{10}$. None of the studied KT patients reported the use of alcoholic beverages. The methodological rigor used to define this NAd behavior may have influenced these results ${ }^{25}$.

The prevalence of nonadherence to treatment dimensions reported in the KT population supports that services include specific interventions to encourage adherence to immunosuppressives and to relevant nonpharmacological treatment components such as physical activity and smoking cessation. KT centers should also emphasize the importance of attendance to consultations for controlling the current health condition ${ }^{7,9,10}$. Evidence of interventions to reduce nonadherence is limited, but studies suggest that efficient measures should be multidimensional and involve a multiprofessional team (doctors, nurses, 
pharmaceutics, psychologists, nutritionists, social assistants). Strategies for assessing specific individual barriers and developing measures that could be integrated into daily life have also been proposed. These personalized care interventions directed to improve self-care management, reinforce self-monitoring and self-efficacy and have the potential to improve adherence to all aspects of treatment included in our study ${ }^{15,16}$.

The first limitation of this study is that the cross-sectional design did not allow for causal inferences. Second, the 20 participating centers were selected by convenience to ensure economic viability and minimize data loss. In the attempts to avoid selection biases, patients were selected randomly for inclusion, but we only screened those with scheduled appointments during the data collection period. Finally, we diagnosed nonadherence using a self-report method, which may have led to underestimation in results ${ }^{22}$.

\section{CONCLUSION}

In this large-sample study, which approached to be representative of the Brazilian KT population, there was an overall high prevalence of nonadherence to immunosuppressives and to nonpharmacological treatment (physical activity, smoking cessation, and keeping appointments). Differences were found among clinical practices in the two health accessdisparate regions, while only nonadherence to smoking cessation occurred more frequently in the R2 region. We propose that the quality of healthcare during follow-up surpassed the limitations in healthcare facilities, which could have potentially influenced the prevalence of nonadherence among KT patients. Nonetheless, transplant service professionals should consider seeking interventions to reduce nonadherence since they may negatively impact post-transplant outcomes.

\section{REFERENCES}

1. De Geest S, Denhaerynck K, Dobbels F. Clinical and economic consequences of nonadherence to immunosuppressive drugs in adult solid organ transplantation. Compliance in solid organ transplantation. In: Grinyó J, editor. International Transplantation Updates. Barcelona, Spain: Permanyer Publications; 2011. p. 63-81.

2. Nevins TE, Nickerson PW, Dew MA. Understanding medication nonadherence after kidney transplant. J Am Soc Nephrol. 2017;28(8):2290-2301. https://doi.org/10.1681/ASN.2017020216.

3. World Health OrganizationSabaté E. Adherence to Long-Term Therapies: Evidence for Action. Geneva: World Health OrganizationWHO; 2003.

4. Denhaerynck K, Dobbels F, Cleemput I, Desmyttere A, Schäfer-Keller P, Schaub $S$, et alet al. Prevalence, consequences, and determinants of nonadherence in adult renal transplant patients: a literature review. Transpl Int. 2005;18(10):1121-1133. https://doi.org/10.1111/j.1432-2277.2005.00176.x.

5. Dew MA, DiMartini AF, De Vito Dabbs A, Myaskovsky L, Steel J, Unruh M, Greenhouse J. Rates and Risk Factors for Nonadherence to the Medical Regimen After Adult Solid Organ Transplantation. Transplantation. 2007;83(7):858-873. https://doi.org/10.1097/01.tp.0000258599.65257.a6.

6. Spivey CA, Chisholm-Burns MA, Damadzadeh B, Billheimer D. Determining the effect of immunosuppressant adherence on graft failure risk among renal transplant recipients. Clin Transplant. 2014;28(1):96-104. doi 10.1111/ctr.12283

7. Zelle DM, Klaassen G, van Adrichem E, Bakker SJL, Corpeleijn E, Navis G. Physical inactivity: a risk factor and target for intervention in renal care. Nat Rev Nephrol. 2017;13(3):152-168. https://doi.org/10.1038/nrneph.2017.44

8. Takahashi A, Hu SL, Bostom A. Physical activity in kidney transplant recipients: a review. Am J Kidney Dis. 2018;72(30):433-443. https://doi.org/10.1053/j.ajkd.2017.12.005

9. Weinrauch LA, Claggett B, Liu J, Finn PV, Weir MR, Weiner DE, et al. smoking Smoking and outcomes in kidney transplant recipients: a post hoc survival analysis of the FAVORIT trial. Int J Nephrol Renov Dis. 2018;11:155-164. https://doi.org/10.2147/IJNRD.S161001 
10. Parker R, Armstrong MJ, Corbett C, Day EJ, Neuberger JM. Alcohol and substance abuse in solid-organ transplant recipients. Transplantation J. 2013;96(12):1015-1024. https://doi.org/10.1097/TP.0b013e31829f7579

11. Taber DJ, Fleming JN, Fominaya CE, Gebregziabher M, Hunt KJ, Srinivas TR, et al. The impact of health care appointment nonadherence on graft outcomes in kidney transplantation. Am J Nephrol. 2017;45(1):91-98. https://doi.org/10.1159/000453554

12. Berben L, Dobbels F, Engberg S, Hill MN, De Geest S. An ecological perspective on medication adherence. West J Nurs Res. 2012;34(5):635-653. doi:10.1177/0193945911434518

13. Denhaerynck K, Berben L, Dobbels F, Russell CL, Crespo-Leiro MG, Poncelet AJ, et al. Multilevel factors are associated with immunosuppressant nonadherence in heart transplant recipients: the international BRIGHT study. Am J Transplant. 2018;18(6):1447-1460. https://doi.org/10.1111/ajt.14611.

14. Sanders-Pinheiro H, Colugnati FAB, Denhaerynck K, Marsicano EO, Medina JOP, De Geest Set al. Multilevel Correlates of Immunosuppressive Nonadherence in Kidney Transplant Patients the Multicenter ADHERE BRAZIL Study. Transplantation. 2020;1. [published online ahead of print, 2020 Mar 2]. Transplantation.2020;10.1097/TP.0000000000003214. https://doi.org/10.1097/TP.0000000000003214

15. Low JK, Williams A, Manias E, Crawford K. Interventions to improve medication adherence in adult kidney transplant recipients: a systematic review. Nephrol Dial Transplant. 2015;30(5):752-761. https://doi.org/10.1093/ndt/gfu204. Epub 2014 Jun 20.

16. Neuberger JM, Bechstein WO, Kuypers DR, Burra P, Citterio F, De Geest S, et al. Practical recommendations for long-term management of modifiable risks in kidney and liver transplant recipients: a guidance report and clinical checklist by the consensus on managing modifiable risk in transplantation (COMMIT) group. Transplantation. 2017;(4 Suppl. 42):;101:S1-S56. https://doi.org/10.1097/TP.0000000000001651.

17. Silva Júnior HT, Felipe CR, Abbud-Filho M, Garcia V, Medina-Pestana JO. The emerging role of Brazil in clinical trial conduct for transplantation. Am J Transplant Off J Am Soc Transplant Am Soc Transpl Surg. 2011;11(7):1368-1375. doi:10.1111/j.1600-6143.2011.03564.x

18. Registro Brasileiro de Transplantes. São Paulo: Associação Brasileira de Transplante de Órgãos. Vol. 24, No. 4, 2018.

19. Costa CKF, Balbinotto Neto G, Sampaio LMB. Eficiência dos estados brasileiros e do Distrito Federal no sistema público de transplante renal: uma análise usando método DEA (Análise Envoltória de Dados) e índice de Malmquist. Cad Saude Publica. 2014;30(8):1667-1679. doi.org/10.1590/0102-311X00121413.

20. Stopa SR, Malta DC, Monteiro CN, Szwarcwald CL, Goldbaum M, Cesar CLG. Use of and access to health services in Brazil, 2013 National Health Survey. Rev Saude Publica. 2017;51(Suppl.lem 1), 3s. https://doi.org/10.1590/s1518-8787.2017051000074.

21. Sanders-Pinheiro H, Colugnati FAB, Marsicano EO, De Geest S, Medina JOP. Prevalence and correlates of nonadherence to immunosuppressants and to health behaviours in patients after kidney transplantation in Brazil - the ADHERE BRAZIL multicentre study: a cross-sectional study protocol. BMC Nephrol. 2018;19(1):41. https://doi.org/10.1186/s12882-018-0840-6 18.

22. Marsicano EO, Fernandes NS, Colugnati F, Grincenkov FR, Fernandes NM, De Geest S, et al. Transcultural adaptation and initial validation of Brazilian-Portuguese version of the Basel assessment of adherence to immunosuppressive medications scale (BAASIS) in kidney transplants. BMC Nephrol. 2013;14(1):108. doi 10.1186/1471-2369-14-108.

23. World Health Organization. Global Recommendations on Physical Activity for Health. Geneva: World Health Organization, 2010. 58 p.

24. Fiore M, Jaen CR, Baker TB, Bailey WC, Benowitz, NL, Curry, SJ, et al. Treating Tobacco Use and Dependence: 2008 Update. Rockville: U.S. Department of Health and Human Services; 2008.

25. World Health Organization. Global Status Report on Alcohol. Geneva: World Health OrganizationWHO; 2004.

26. Takahashi A, Hu SL, Bostom A. Physical Activity in Kidney Transplant Recipients: A Review. Am J Kidney Dis Off J Natl Kidney Found. 2018;72(3):433-443. https://doi.org/10.1053/j.ajkd.2017.12.005 
27. Berben L, Engberg SJ, Rossmeiss A, Gordon EJ, Kugler C, Schmidt-Trucksäss A, Klem ML, Sereika SM, Simone P, Dobbels F, De Geest SMet al. Correlates and Outcomes of Low Physical Activity Posttransplant: A Systematic Review and Meta-Analysis. Transplantation. 2019;103(4):679-688. https://doi.org/10.1097/TP.0000000000002543

28. Masajtis-Zagajewska A, Muras K, Nowicki M. Effects of a structured physical activity program on habitual physical activity and body composition in patients with chronic kidney disease and in kidney transplant recipients. Exp Clin Transplant. 2019;17(2):155-164. https://doi.org/10.6002/ect.2017.0305

29. Araújo MEA, Silva MT, Andrade KRC, Galvão TF, Pereira MG. Prevalência de utilização de serviços de saúde no Brasil: revisão sistemática e metanálise. Epidemiol Serv SaúdeEpidemiol E Serviços Saúde. 2017;26(3):589-604. https://doi.org/10.5123/s1679-49742017000300016

30. Albuquerque MV de, Viana AL d'DÁvila, Lima LD de, Ferreira MP, Fusaro ER, lozzi FL. Desigualdades regionais na saúde: mudanças observadas no Brasil de 2000 a 2016. Cienc Saude Colet. 2017;22(4):1055-1064. https://doi.org/10.1590/1413-81232017224.26862016

*The ADHERE BRAZIL study team includes the following individuals: Helio Tedesco-Silva ${ }^{\mathrm{IV}}$, Paula F.C.B.C. Fernandes ${ }^{\mathrm{V}}$, Marilda Mazzali ${ }^{\mathrm{VI}}$, Pedro A.M. Souza ${ }^{\mathrm{VII}}$, Roberto C. Manfro ${ }^{\mathrm{VIII}}$, Alvaro Pacheco-Silva ${ }^{\mathrm{IX}}$, Gustavo F. Ferreira ${ }^{\mathrm{X}}$, Elias David-Neto ${ }^{\mathrm{XI}}$, Valter D. Garcia ${ }^{\mathrm{XII}}$, Carlos G.W.C. Marmanillo ${ }^{\mathrm{XIII}}$, Silvia R. Cruz ${ }^{\mathrm{XIV}}$, Luciane M. Deboni ${ }^{\mathrm{XV}}$, Mário Abbud-Filho ${ }^{\mathrm{XVI}}$, Teresa C.A. Ferreira ${ }^{\mathrm{XVII}}$, Maurício G. Pereira ${ }^{\mathrm{XVII}}$, Deise B.M. Carvalho ${ }^{\mathrm{XIX}}$, Sergio Wyton ${ }^{\mathrm{XX}}$, Giuseppe C. Gatto ${ }^{\mathrm{XXI}}$, and Rafael F. Maciel ${ }^{\mathrm{XXII}}$.

${ }^{\mathrm{v}}$ Universidade Federal do Ceará. Fortaleza, CE, Brasil

${ }^{\mathrm{V}}$ Universidade de Campinas. Campinas, SP, Brasil

${ }^{\mathrm{VII}}$ Santa Casa de Misericórdia de Belo Horizonte. Belo Horizonte, MG, Brasil

VIII Universidade Federal do Rio Grande do Sul. Hospital das Clínicas de Porto Alegre. Porto Alegre, RS, Brasil

${ }^{\mathrm{x}}$ Hospital Israelita Albert Einstein. São Paulo, Brasil

${ }^{x}$ Santa Casa de Juiz de Fora. Juiz de Fora, MG, Brasil

${ }^{\mathrm{xI}}$ Universidade de São Paulo. Hospital das Clínicas de São Paulo. São Paulo, SP, Brasil

${ }^{\mathrm{XII}}$ Santa Casa de Porto Alegre. Porto Alegre, RS, Brasil

${ }^{\mathrm{XIII}}$ Hospital Angelina Caron. Curitiba, PR, Brasil

${ }^{\mathrm{XIV}}$ Universidade Federal do Para. Hospital Ofir Loyola. Belém, PA, Brasil

${ }^{x v}$ Fundação Prorim. Hospital Municipal de São José. Joinville, SC, Brasil

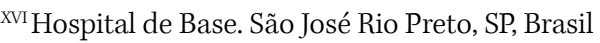

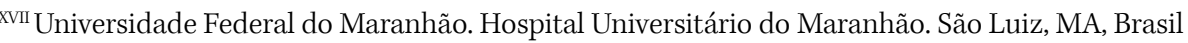

xVIII Universidade Federal do Rio Grande do Norte. Hospital Onofre Lopes. Natal, RN, Brasil

${ }^{x I x}$ Hospital São Francisco de Assis da Providência de Deus. Rio de Janeiro, RJ, Brasil

${ }^{\mathrm{xx}}$ Hospital São João de Deus. Divinópolis, MG, Brasil

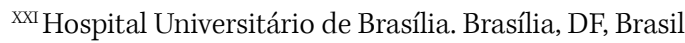

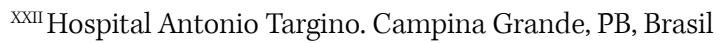

Funding: Helady Sanders-Pinheiro and Elisa de Oliveira Marsicano received grants through scholarships from Coordenação de Aperfeiçoamento de Pessoal de Nível Superior (Capes - Financial code 001). The study received internal grants from Fundação Instituto Mineiro de Estudos e Pesquisas em Nefrologia (IMEPEN) and research grants from Libbs Pharmaceutical Ltda. and Astellas Pharma Brazil Ltd. The internal grants do not have a grant number.

Authors' Contribution: Conception, planning, analysis, interpretation of results and writing of the manuscript: EOM, FC, SD, HS.

Conflict of Interest: The authors declare no conflict of interest. 